\title{
Propuesta didáctica: Andalucía y la publicidad
}

LORETO GÓMEZ LÓPEZ-QUIÑONES

Universidad de Granada

loreto@cmli.es

\begin{abstract}
Resumen: A través del uso de la publicidad, vamos a plantear una propuesta didáctica que intente cubrir una serie de aspectos socioculturales de Andalucía. Planteada en tres sesiones, y utilizando carteles, anuncios, eslóganes y publicidad audiovisual, intentamos ofrecer al alumnado, de forma amena, una serie contenidos gramaticales y léxicos como las oraciones interrogativas e imperativas, el subjuntivo y algunos de sus usos, las estructuras finales, las frases comparativas, el vocabulario relacionado con los viajes, el entorno, el ocio, las tradiciones y la cultura, así como algunos modismos y expresiones idiomáticas. También introduciremos algunas de las figuras retóricas más utilizadas en castellano con fines publicitarios. No obstante, también pretendemos ayudar a los estudiantes de ELE a entender mejor la cultura andaluza vista desde la mirada autóctona y desde la mirada foránea, como algo en continuo cambio y más allá de los estereotipos.
\end{abstract}

Palabras clave: Andalucía, Publicidad, Competencia socio-cultural, propuesta didáctica

\section{Didactic Proposal: Andalucía and its publicity}

Abstract: Through the use of publicity, we are going to present a didactic proposal that tries to assess a series of sociocultural aspects about Andalucía. Organized in three sessions, and using posters, advertisements, slogans and audivisual publicity, one tries to teach, in a funny and entertainig way, a series or grammatical and lexical contents such as the interrogations, commands, the subjunctive mode and vocabulary related to travels, environnement, traditions and culture. Moreover, one also aims at providing ELE students with a better understanding of Andalusian culture, from a native and a foreign perspective, as something that is continuously evolving and that goes beyond sterotypes.

Key words: Andalucía, Publicity, Sociocultural competence, didactic proposal

\section{Introducción}

En este artículo, presentamos una propuesta didáctica para explotar el uso de la publicidad en la clase de ELE. La publicidad es una herramienta enormemente útil a la hora de enseñar determinados contenidos y competencias socioculturales. De hecho, muchos anuncios publicitarios pretenden ser un reflejo de la sociedad española, de sus valores y de su estilo de vida (Robles, 2004). En concreto, la publicidad turística ha querido mostrar una parte muy parcial y muy positiva de la sociedad, y también esta selección de información que intenta condicionar cómo queremos que nos vean desde fuera resulta muy útil para entender las preocupaciones y anhelos de una sociedad. En gran parte de esta publicidad que viene proyectando nuestro país desde los años de la 
dictadura, Andalucía ha ocupado un lugar protagonista porque mucha de la iconografía que se ha proyectado estaba relacionada con el imaginario andaluz (Cano, 2012).

Aparte de esto, los anuncios publicitarios también resultan enormemente útiles para enseñar determinados contenidos léxicos y gramaticales. De hecho, la publicidad cada vez se ha hecho más presente los manuales de ELE, los congresos, los materiales docentes y, en general, las clases de ELE. A través de esta propuesta, proponemos una serie de actividades motivadoras para los estudiantes y que, además, resulten útiles para enseñar determinados contenidos lingüísticos (el imperativo, los comparativos, las oraciones finales), pero también para centrarnos en determinados aspectos socioculturales (la relación de Andalucía con el turismo, la diferencia entre la percepción autóctona y foránea dentro de la propia comunidad autónoma, la evolución histórica de la sociedad Andaluza, etc.)

\section{Marco Teórico}

\subsection{Competencia socio-cultural en la clase de ELE.}

En la actualidad, está más que aceptado entre los profesores de ELE que la competencia gramatical no basta para asegurar la correcta adquisición de una lengua ni para que la comunicación sea fluida, adecuada y eficaz. Junto a los conocimientos gramaticales, las clases de lengua cada vez se centran más en la competencia cultural: "La cultura está estrechamente unida a la lengua y, por este motivo, el aprendiente de una L2 debe adquirir una dimensión cultural, unos conocimientos socioculturales [...] que le permitan conseguir una comunicación adecuada y eficaz» (Pinar García, 2012: 8). Queda claro, pues, que es imprescindible el desarrollo de la competencia cultural en la enseñanza del idioma, $y$, sin embargo, tradicionalmente, el componente cultural no se ha llegado a integrar de una forma globalizadora en las aulas, como afirma Kramsch: «In practice, teachers teach language and culture, or culture in language, but not language as culture» (Kramsch, 1996: 6).

Esta competencia cultural es esencial para alcanzar la competencia comunicativa. Fue Hymes el primero en hablar de este concepto y lo definió como un saber «cuándo hablar, cuándo no, y de qué hablar, con quién, cuándo, dónde, y en qué forma» (Hymes, 1971). Desde entonces, han sido muchos los autores que han ido matizando y completando esta primera definición de Hymes. Por ejemplo, Kramsch define esta enseñanza de la cultura como un espacio de tensión entre los significados del aprendiz de lengua y los del hablante nativo (2010: 24). De hecho, en los últimos años, ha ido cobrando importancia el concepto de competencia intercultural en el que la cultura se presenta como algo más dinámico y en continuo cambio y en el que tanto los profesores como los alumnos pasan a jugar un papel de mediadores culturales. En palabras de Madrona, «mientras que la competencia comunicativa supone solo conocer, la competencia intercultural implica la capacidad de actuar» (2021: 21). La idea principal de la competencia intercultural sería, de este modo, dejar de usar en el aula al hablante nativo como un espejo en el que reflejarse, dada la dificultad que de los estudiantes alcancen ese modelo; de esta forma, lo importante en el aula pasaría a ser la presencia de hablantes no nativos que negocian con los nativos y que alcanzan una comunicación satisfactoria para ambos, pero consiguiendo preservar su identidad cultural (Madrona Fernández, 2021: 21). 
Lo que es indudable a estas alturas es que la presencia del elemento cultural en la clase de lengua es imprescindible y que la enseñanza-aprendizaje de la lengua y de la cultura son indisociables: "At any rate, foreign language learning is foreign culture learning, and, in one form or another, culture has, even implicitly, been taught in the foreign language classroom» (Thanasoulas, 2001: 2). El impacto que la cultura ejerce en la lengua es enorme. De hecho, la lengua no se puede disociar del contexto cultural en el que se origina, se desarrolla y evoluciona. Por tanto, para que nuestro alumnado alcance la competencia lingüística, es imprescindible que desarrolle también la competencia cultural.

Obviamente, no se trata de presentar a los alumnos un caudal de hechos y productos culturales que no serán significativos para ellos, y que tampoco estarán relacionados con sus experiencias ni, probablemente, con sus necesidades. Más bien se trata de intentar tener muy presente la influencia mutua entre lengua y cultura a la hora de crear significados, ya que éstos se van construyendo a través de la interacción humana y de la comunicación a través de las lenguas. Por lo tanto, el estudiante de ELE tendrá mayor competencia comunicativa, es decir, podrá comunicarse de una forma más eficiente, cuanto mayor sea su conocimiento de las distintas realidades en las que viven y se comunican los hispanohablantes.

\subsection{El uso de la publicidad en la clase de ELE}

Una vez aclarada la importancia de la cultura para desarrollar la competencia comunicativa, es importante analizar cómo presentar todos esos aspectos culturales en la clase de ELE. La cultura ya no puede presentarse de forma aislada o como un corpus de conocimientos elevados o como una acumulación de estereotipos; más bien debe presentarse como algo cotidiano que comparten los hablantes de una lengua y que es necesario para el éxito del acto comunicativo (Miquel López, 2004: 513). Como decíamos más arriba, para evitar presentar los contenidos gramaticales como una amalgama de hechos, es importante presentar la cultura contextualizada con y en la lengua:

Para asegurar la correcta transmisión de los contenidos culturales, sean del tipo que sean, es imprescindible que éstos aparezcan bien contextualizados, de tal modo que el alumno pueda interpretar correctamente la información e inferir la relación entre uso de la lengua y situación comunicativa (Robles Ávila, 2004:723).

Pues bien, para contextualizar esos contenidos culturales, la publicidad se presenta como un gran aliado; como afirma Robles, «los anuncios publicitarios, especialmente aquellos en soporte audiovisual, se presentan como una herramienta muy adecuada para llevar al aula de E/LE ciertos casos de cultura en la lengua contextualizados» (2004: 723). Lo cierto es que la publicidad suele presentar de forma muy clara y concisa muchos de esos referentes culturales que «pueden definirse como aquellos elementos, imágenes, ideas, realidades y productos culturales comunes y compartidos por la comunidad» (Pinar García, 2012: 9). La publicidad suele apelar a sentimientos universales, pero también puede mostrar aspectos socioculturales básicos que diferencian a los países y sus respectivas culturas (Pinar García, 2012: 6). Como afirma Pinar, la publicidad es un medio ideal para transmitir la dimensión cultural que nuestros alumnos aspiran a conocer ya que presenta estilos de vida comunes, anhelos, expectativas, gustos, conductas, talantes, roles sociales, consumo hábitos alimenticios, 
ocio y experiencias vitales. La publicidad es también un vehículo para difundir valores y opiniones que reflejan una realidad sociocultural determinada y cuyo conocimiento es irremplazable para desenvolverse en la sociedad cuya lengua estamos aprendiendo (2012:10).

En este sentido, sería interesante diferenciar entre los anuncios que van dirigidos a la propia comunidad reflejo de esa publicidad y los anuncios que van dirigidos a comunidades foráneas. Por un lado, están

los anuncios institucionales, relacionados con el medio ambiente, el consumo de agua, el fomento de la lectura, la lucha contra la droga o los malos tratos, con la oferta de formación educativa, la promoción del uso del transporte público [...] Esta publicidad enseña imágenes, ideas y realidades, creencias y valores compartidos por la comunidad y que configuran su identidad cultural (Pinar García, 2012: 11).

$\mathrm{Y}$, por otra parte, están los anuncios que muestran con pinceladas más gruesas los aspectos más atractivos (que, en ocasiones, son los más estereotipados) de esa sociedad. La finalidad de esta última publicidad es la de mostrar el lado más luminoso y positivo, mostrar sus lugares de interés y sus productos más llamativos para poder atraer, por ejemplo, al turismo:

La publicidad, en este campo, desempeña la función de un enviado directo, de un embajador, el cual se encarga de transmitir una imagen agradable, la mejor de todas, y a la medida de la idea que el público se hace de un sitio y de los que en él viven (Dahdá, 2006: 60).

Para nosotros, como profesores de ELE, lo más interesante de esta publicidad turística es que, a pesar de que también intenta vender, a diferencia de otro tipo de publicidad, también muestra una idiosincrasia y unos valores que no se ven en otra suerte de productos como la publicidad de cosméticos o de coches: «va más allá de la balanza comercial, de ahí que este ámbito se apelen valores, como el afán de saber, de conocer, el cosmopolitismo y la apertura a otras culturas» (Martí Marco, 2007:122). Esta actitud de apertura y de curiosidad, este respeto por otras realidades, este afán de conocimiento y esta actitud intercultural son, sin duda, un gran aliado para el profesor de ELE.

La publicidad ha acompañado a la humanidad, de una u otra forma, desde tiempos remotos $\mathrm{y}$, suele ofrecer una fuerte influencia en un camino de idea vuelta: por una parte, ha demostrado ser un claro reflejo de la sociedad que la produce y, al mismo tiempo, ejerce sobre esa sociedad un impacto que, junto a otros numerosísimos factores, acaba conformándola: «No se podría entender la publicidad sin recurrir a la época y el lugar en el que se produce y la determina, porque los mensajes publicitarios dependen para su configuración del contexto social y cultural que les da sentido» (Hellín Ortuño, 2007: 18). Por lo tanto, la publicidad se convierte en un medio utilísimo para conocer una sociedad y su lengua, y hablar sobre y a propósito de ambas.

Dado su enorme poder de influencia en la sociedad actual, no es de extrañar que las instituciones educativas muestren un gran interés en la publicidad y que ésta se incorpore, cada vez más, a los materiales didácticos en la clase de ELE. Aparte de todo el contenido audiovisual, la publicidad ofrece una gran cantidad de posibilidades a la hora de enseñar contenidos lingüísticos:

Además de la vertiente sociocultural, en la clase de ELE se puede sacar partido de los anuncios en el código lingüístico para enseñar cierto vocabulario o estructuras morfosintácticas, en el icónico para manejarse con imágenes impresas o audiovisuales y en el no verbal para adquirir, 
por ejemplo, la mímica y los gestos propios que acompañan a una lengua concreta (Pozo García, 2012: 22).

En el caso concreto de nuestra propuesta didáctica, vamos a centrarnos en los principales contenidos de los que habla Pozo en su trabajo Los anuncios institucionales en la clase de español del turismo a nivel morfosintáctico es interesante hablar de lo que Pozo ha denominado la «hegemonía del imperativo» (2012: 25); pero también predominarán el presente $y$ el futuro en el modo indicativo, los enunciados interrogativos, las estructuras condicionales las estructuras causales y finales, los comparativos y los superlativos. Y a nivel léxico-semántico, abundarán las anáforas, las metáforas, el paralelismo, la antítesis, la personificación, los juegos de palabras, y la hipérbole, las frases hechas, los refranes, los modismos (Pozo García, 2012). Además, uno de los principales aspectos de la publicidad es que su discurso es persuasivo, por lo que se podría tratar con los alumnos muchas técnicas lingüísticas para trabajar la persuasión (Argüelles Díaz, 2015: 34).

Por último, nos gustaría terminar esta introducción insistiendo en el aspecto motivador de la publicidad. Al tratarse de documentos reales, es un incentivo para los alumnos, que lo perciben como algo ameno y divertido. El alumnado percibe la presencia de la publicidad en el aula «más como un regalo que como un elemento pedagógico per se» (Bohorquez Rodríguez, 2013: 81). De ahí que la publicidad haya sido, y siga siendo, un aliado tan potente para los profesores de ELE, que han sabido ver su utilidad para estimular el interés del alumno, dinamizar el aula y despertar su curiosidad

\section{Propuesta didáctica}

Objetivos didácticos: Expresar y justificar opiniones, valorar hechos, personas, objetos y lugares, expresar acuerdo y desacuerdo, comparar personas, objetos y lugares, describir personas, objetos y lugares, atraer la atención y dirigirse a alguien, expresar intereses, gustos y preferencias, pedir información, preguntar información personal, preguntar si se está de acuerdo, preguntar por gustos y preferencias, dar indicaciones, dar órdenes, persuadir, vocabulario de las lenguas y del lenguaje en el aula.

Objetivos competenciales: Usar el lenguaje como medio de transmisión de valores, fomentar los valores interculturales, la diversidad lingüística, la dimensión europea de la educación y el principio de igualdad de oportunidades y derechos entre hombres y mujeres. Usar otras disciplinas como la publicidad, en relación con el lenguaje fomentando además la capacidad creativa del alumno. Hacer uso de las experiencias y conocimientos previos del alumno, aprender a aprender.

Contenidos gramaticales: Oraciones interrogativas e imperativas, repaso del subjuntivo $\mathrm{y}$ algunos de sus usos, pronombres reflexivos, vocabulario relacionado con los viajes, vocabulario del entorno, del tiempo libre y del ocio, del tiempo libre y el ocio, de los transportes, alojamientos, tradiciones y cultura, figuras retóricas (anáfora, paralelismos, aliteraciones, metáforas, antítesis, personificación, hipérbaton, hipérbole), estructuras finales, frases comparativas reconocimiento de modismos y expresiones idiomáticas.

Nivel: B2 (según el MCER)

Materiales: carteles e imágenes publicitarias que se recogen en esta propuesta, pizarra y/o proyector, acceso a internet. 
Temporalización: Cada sesión está diseñada para durar aproximadamente 3 horas.

\section{Bibliografía}

ARgÜELles DíAZ, Alba. 2015. Los anuncios en la clase de ELE: una propuesta didáctica. Universidad de Oviedo. Recuperado el 23/12/21, de https://digibuo.uniovi.es/dspace/handle/10651/33779.

BOHORQUEZ RODRÍGUEZ, Emilio. 2013. « ¿Una pausa y volvemos! La publicidad en el aula de ELE: una propuesta didáctica». En M. Jimeno Panés (ed.) Actas del Primer Congreso Internacional de Didáctica del Español como Lengua Extranjera. Budapest: Instituto Cervantes de Budapest, 81-106.

CANO FigueroA, Cinta María. 2012. «Hacia la globalización del tópico andaluz: Andalucía te quiere». Questiones publicitarias: revista internacional de comunicación y publicidad, 17, 54-70.

DAHDÁ, Jorge. 2006. La publicidad turística. Madrid: Trillas.

Hellín OrtuÑo, Pedro Antonio. 2007. Publicidad y valores postmodernos. Madrid: Visionnet-Siranda.

HyMES, Dell Hathaway. 1971. On Communicative Competence. Filadelfia : University of Pensylvannia Press.

KrAMSCH, Claire. 2010. ( $1^{\text {a }}$ ed. 1993). Context and culture in language teaching. Oxford: Oxford University Press.

KRAMSCH, Claire. 1996. «The cultural component of language teaching». Language, Culture and Curriculum, 8(12), 83-92.

MADRONA FERNÁNDEZ, Alberto. 2021. La construcción de la competencia intercultural del alumnado y del papel de mediador intercultural del profesorado a través del análisis del manual de ELE Gente hoy 1. [Trabajo de fin de máster] Universidad de Lleida. Recuperado el 23/12/21, de https://repositori.udl.cat/handle/10459.1/71410

Martí MARCo, María Rosario. 2007. «Turismo y publicidad. Análisis del discurso publicitario de las campañas internacionales de Turespaña en países de lengua alemana». En M. Borrueco Rosa. (ed.), La publicidad en el turismo. Sevilla: Junta de Andalucía, Conserjería de Turismo, Comercio y Deporte, Colección Estudios lingüísticos y turismo 2, 115-134.

MiQUEL LÓPEZ, Lourdes. 2004. «La subcompetencia sociocultural». En J. Sánchez Lobato y I. Santos Gargallo (ed.) Vademecum para la formación de profesores. Enseñar español como L2. Madrid: Sgel, 511-531.

PINAR GARCíA, Alex. 2012. "Cultura y publicidad en la clase de ELE: Propuesta didáctica para un curso de conversación». MarcoELE. Revista de Didáctica Español Lengua Extranjera, 14, 3-93.

Pozo García, José Carlos. 2012. Los anuncios institucionales en la clase de español del turismo: Una propuesta didáctica. [Trabajo de fin de máster] Universidad de Málaga. Recuperado el 30/08/21, de https://www.educacionyfp.gob.es/mc/redele/biblioteca- 
virtual/numerosanteriores/2012/memoria-master/jose-carlos-pozo.html

Robles ÁvilA, Sara. 2004. «Lengua en la cultura y la cultura en la lengua: la publicidad como herramienta didáctica en clase de ELE». En J. Coloma Maestre (ed.). Actas del XIII Congreso International de la Asociación para la Enseñanza del Español como Lengua Extranjera. Murcia: ASELE, 720-730.

ThanAsoulas, Dimitrios. 2001. "The importance of teaching culture in the foreign language classroom». Radical pedagogy, 3, 1-25. 


\section{PRIMERA SESIÓN: ANDALUCÍATE}

1. Mira estos carteles publicitarios de Andalucía y responde a las preguntas:
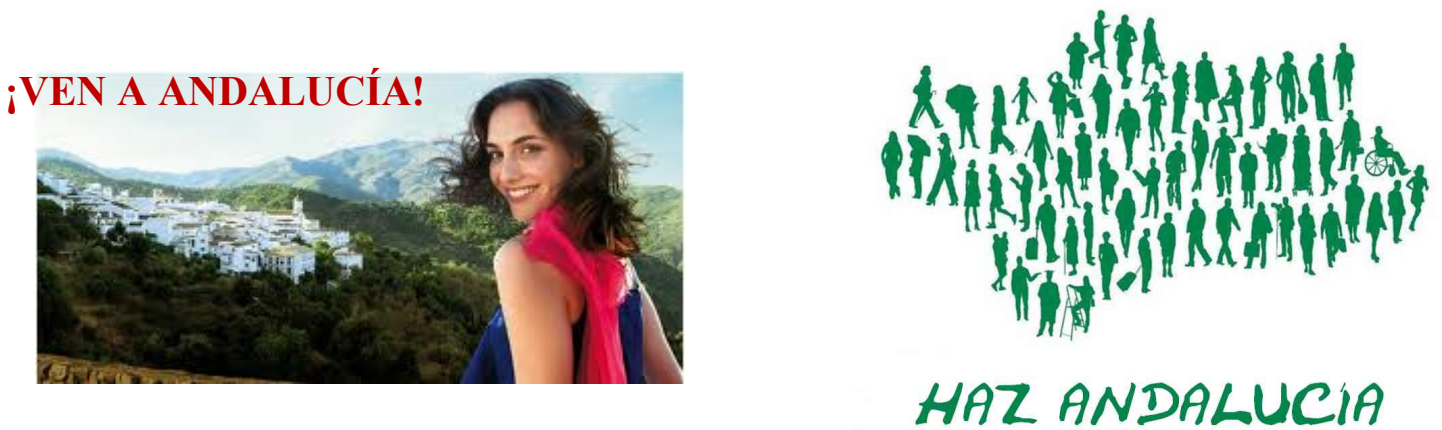

a) ¿Te gustan estos carteles publicitarios?

b) ¿A quién crees que van destinados estos anuncios? ¿Qué intención tienen? ¿Crees que los dos carteles van dirigidos al mismo público?

c) ¿Crees que funcionan? ¿Crees que atraen nuestra atención? ¿Por qué?

d) ¿Sueles mirar carteles publicitarios en la calle?

e) ¿La publicidad influye en tus decisiones para elegir?

f) En tu opinión, ¿cuáles son los aspectos más importantes de un anuncio publicitario? ¿las formas, los colores, el texto?

g) ¿Conoces la forma verbal que aparece en estos anuncios?

h) ¿Qué forma verbal suele aparecer con más frecuencia en los anuncios de tu país? 
IMPERATIVO AFIRMATIVO

\begin{tabular}{|c|c|c|c|}
\hline & TRABAJ-AR & COM-ER & ESCRIB-IR \\
\hline (tú) & Trabaj-a & Com-e & Escrib-e \\
(él, ella, usted) & Tabaj-e & Com-a & Escrib-a \\
(nosotros/as) & Trabaj-emos & Com-amos & Escrib-amos \\
(vosotros/as) & Trabaj-ad & Com-ed & Escrib-id \\
(ellos/as, ustedes) & Trabaj-en & Com-an & Escrib-an \\
\hline
\end{tabular}

\section{IMPERATIVOS IRREGULARES}

(Normalmente el imperativo tiene las mismas irregularidades que el presente de indicativo):

\begin{tabular}{|c|c|c|c|c|}
\hline & CERRAR & VOLVER & JUGAR & PEDIR \\
\hline (tú) & Cierra & Vuelve & Juega & Pide \\
(él, ella, usted) & Cierre & Vuelva & Juegue & Pida \\
(nosotros/as) & Cerremos & Volvamo & Juguemo & Pidamos \\
(vosotros/as) & Cerrad & Volved & Jugad & Pedid \\
(ellos/as, ustedes) & Cierren & Vuelvan & Jueguen & Pidan \\
\hline
\end{tabular}

OTROS IMPERATIVOS COMPLETAMENTE IRREGULARES

\begin{tabular}{|c|c|c|c|c|c|c|}
\hline & DECIR & HACER & IR & PONER & SALIR & VENIR \\
\hline (tú) & Di & Haz & Ve & Pon & Sal & Ven \\
(él, ella, usted) & Diga & Haga & Vaya & Ponga & Salga & Venga \\
(nosotros-as) & Digamo & Hagamos & Vayamos & Pongamo & Salgamos & Vengamos \\
(vosotros/as) & Decid & Haced & Id & Poned & Salid & Venid \\
(ellos/as, ustedes) & Digan & Hagan & Vayan & Pongan & Salgan & Vengan \\
\hline
\end{tabular}

\section{USOS DEL IMPERATIVO}

Invitar y ofrecer: ;Coge una galleta!

Conceder permiso: ¡Pasa! ¡Siéntese!

Dar órdenes: ¡Ven aquí!

Dar instrucciones: Tome dos pastillas al día

Dar consejos: Conduce con cuidado

El imperativo de la primera persona del plural se usa muy poco. Es

frecuente utilizar: Vamos a + infinitivo

¡Salgamos! > ¿Vamos a salir!

¡Comamos! $>$ ¡Vamos a comer! 
2. En parejas escribe tu propio texto publicitario para cada uno de estos carteles sobre Andalucía destinados a atraer a los turistas. Utiliza, por lo menos, un imperativo afirmativo:
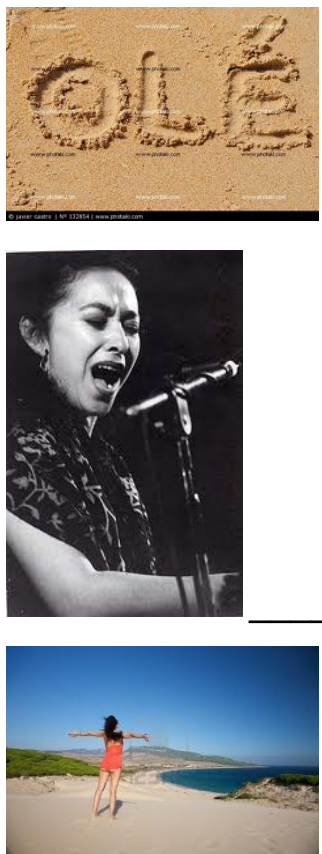

3. Ahora vamos a hacer lo mismo que en el ejercicio anterior pero esta vez los anuncios van a ir destinados a los propios andaluces:
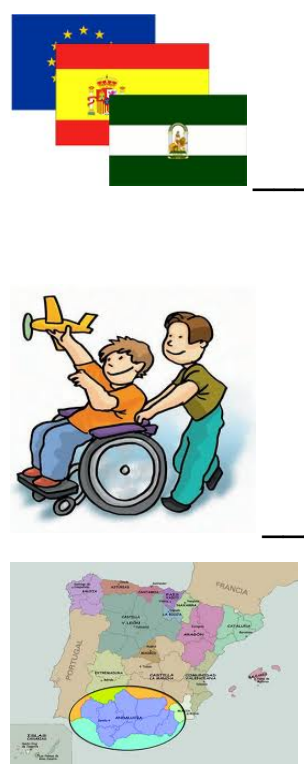
4. Mira el siguiente spot publicitario atentamente. En grupo, vais a ponerle voz usando el imperativo afirmativo. También podéis escribirlo y grabar vuestras propias voces:

https://www.youtube.com/watch?v=iEd1Fi8qAy0

5. Mira el siguiente spot publicitario y cambia todas las frases que aparecen sustituyendo el imperativo por una frase interrogativa:

https://www.youtube.com/watch?v=JFbQT3 tKCQ

\section{SEGUNDA SESIÓN: FIGÚRATE}

\begin{tabular}{|c|c|}
\hline \multicolumn{2}{|c|}{$\begin{array}{l}\text { LA PUBLICIDAD UTILIZA CON MUCHA FRECUENCIA LAS } \\
\text { FIGURAS RETÓRICAS: }\end{array}$} \\
\hline \multicolumn{2}{|c|}{$\begin{array}{l}\text { Las figuras retóricas son formas poco frecuentes de usar el lenguaje para } \\
\text { conseguir más expresividad o belleza en el lenguaje } \\
\text { El uso de las figuras retóricas en muy frecuente en la publicidad para captar la } \\
\text { atención del receptor, para producir un efecto de originalidad, para } \\
\text { sorprender, persuadir y emocionar. Veamos algunas figuras retóricas: }\end{array}$} \\
\hline $\begin{array}{l}\text { Anáfora: Repetición de una o varias } \\
\text { palabras al principio del enunciado. }\end{array}$ & $\begin{array}{l}\text { Personificación: Atribución de } \\
\text { cualidades y sentimientos humanos a } \\
\text { animales y/o realidades inanimadas. }\end{array}$ \\
\hline $\begin{array}{l}\text { Metáfora: Sustitución de una cosa por } \\
\text { otra a través de algún tipo de similitud o } \\
\text { de asociación. }\end{array}$ & Hipérbole: Exageración. \\
\hline $\begin{array}{c}\text { Paralelismo: } \text { Repetir alguna estructura } \\
\text { varias veces, pero cambiando algún } \\
\text { elemento. }\end{array}$ & $\begin{array}{c}\text { Antítesis: Oposición o contraste entre } \\
\text { dos términos contrarios o } \\
\text { complementarios. }\end{array}$ \\
\hline $\begin{array}{l}\text { Juego de palabras: Uso de una misma } \\
\text { palabra o de palabras homónimas o } \\
\text { homófonas en dos sentidos distintos. }\end{array}$ & $\begin{array}{c}\text { Hipérbaton: Alteración del orden } \\
\text { habitual } \\
\text { de las palabras en una frase. }\end{array}$ \\
\hline
\end{tabular}


1. Mira estos tres carteles publicitarios y en parejas responde a las siguientes preguntas.
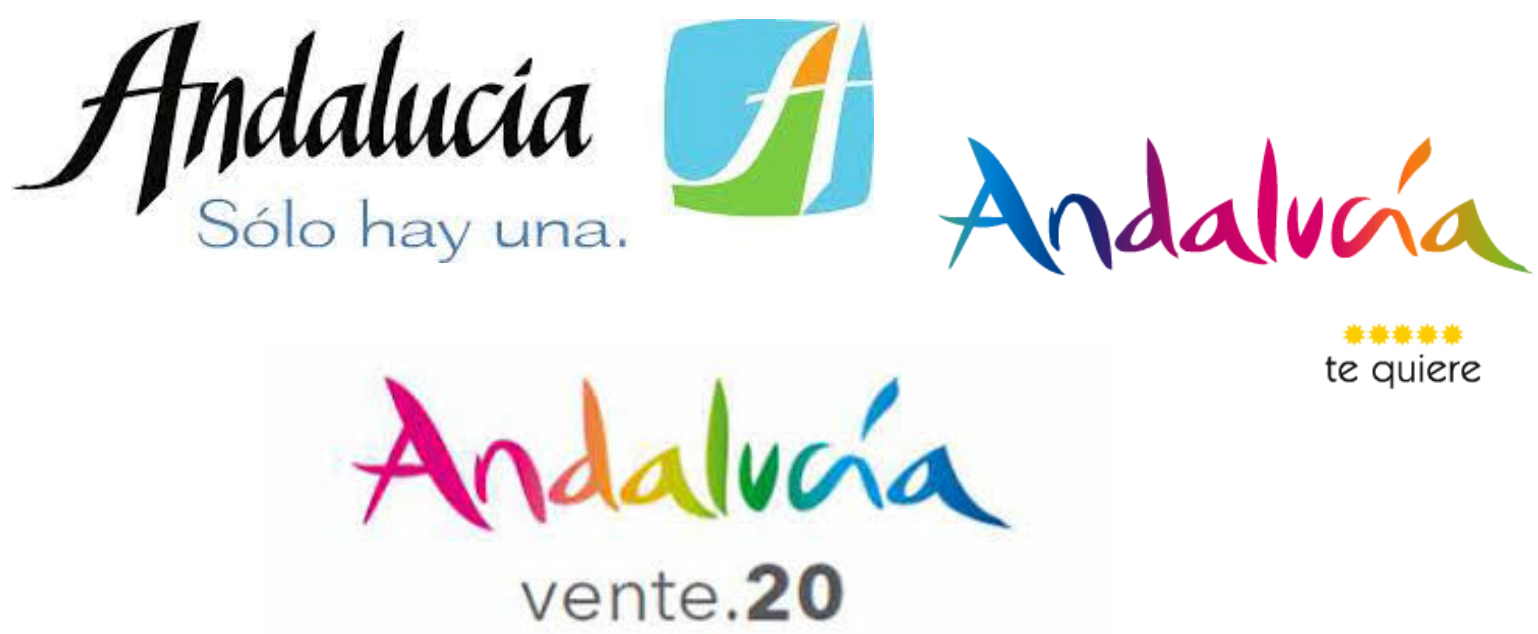

te quiere

a) ¿Te gusta estos tres anuncios? ¿Por qué?

b) ¿Cuál crees que es su principal objetivo? ¿Crees que funcionan? ¿Por qué?

c) ¿Qué te llama la atención del orden de las palabras del primer anuncio?

d) En cuanto al segundo anuncio, ¿es normal que un lugar o una cosa quieran a una persona?

e) ¿Cuál es el juego de palabras del tercer anuncio?

f) Identifica en estos tres carteles publicitarios estas tres figuras retóricas que hemos visto más arriba: personificación, hipérbaton y juego de palabras.

g) En tu opinión, ¿Por qué se usan la personificación, la el hipérbaton y el juego de palabras en estos anuncios?

2. En el siguiente anuncio, podrás encontrar una serie de figuras retóricas que hemos explicado más arriba: Anáforas, paralelismos, metáforas $y$ antítesis. Localiza esas figuras retóricas en el anuncio. ¿Con qué finalidad crees que se usan? ¿En tu opinión, funcionan? ¿Existe en tu idioma una forma similar de jugar con el lenguaje?

https://www.youtube.com/watch?v=-oEygFpWN9M 
3. Vuelve a visualizar el anuncio del ejercicio final. A partir del minuto del minuto 1:06 se usan estructuras de frases finales ¿Puedes deducir por qué a veces se usa el infinitivo y a veces el subjuntivo?

https://www.youtube.com/watch?v=-oEygFpWN9M

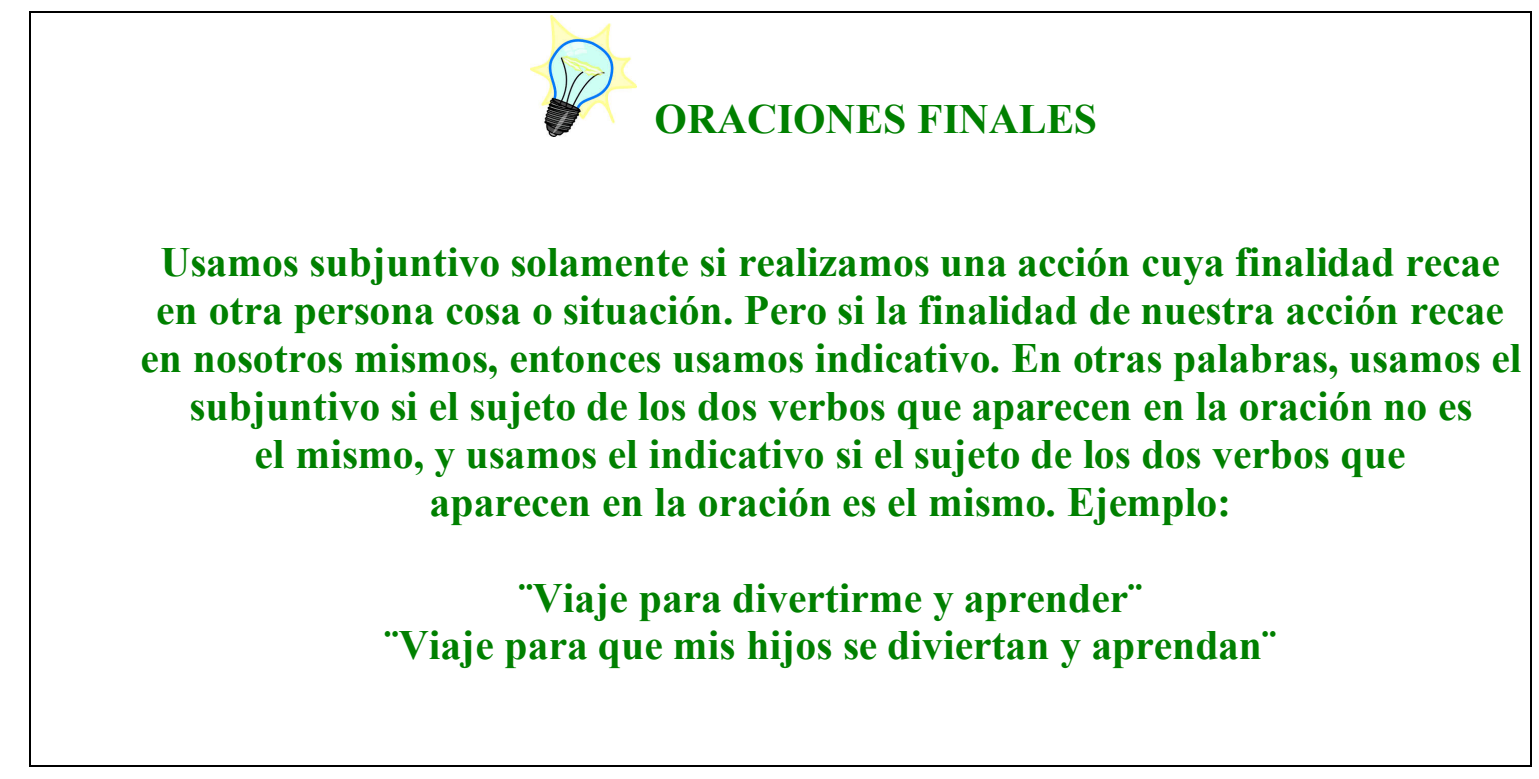

\section{TERCERA SESIÓN: COMPÁRATE}

1. La publicidad turística siempre ha intentado transmitir valores positivos. Mira estos dos carteles responde a las siguientes preguntas.

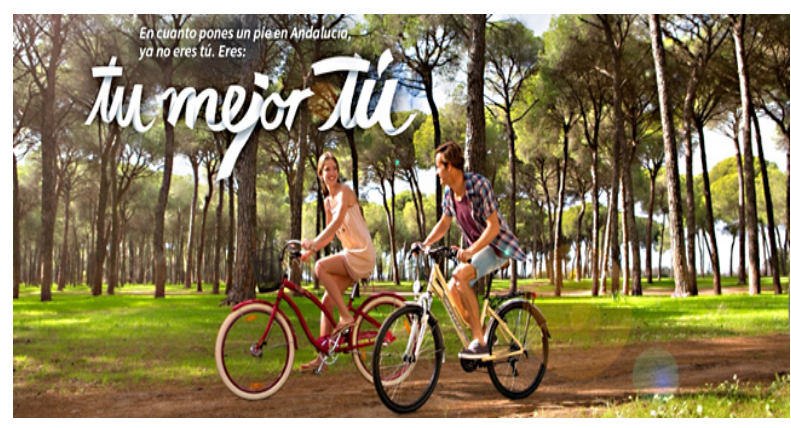

\section{ANDALUCES, DE NUEVO \\ LEVANTAOS}

28F DIA DE ANDALUCIA

a) En tu opinión, ¿a qué público va destinado el primer anuncio? ¿y el segundo?

b) ¿Qué mensaje intenta trasmitir el primer anuncio? ¿Qué imagen de Andalucía proyecta? ¿Qué comportamiento intenta provocar en los receptores?

c) ¿Qué mensaje intenta trasmitir el segundo anuncio? ¿Qué imagen de Andalucía proyecta? ¿Qué comportamiento intenta provocar en los receptores? 
d) ¿Qué diferencias puedes apreciar entre estos dos carteles en cuanto los colores, la imagen, la estructura, el tipo de letra, el mensaje escrito? Utiliza estructuras comparativas.

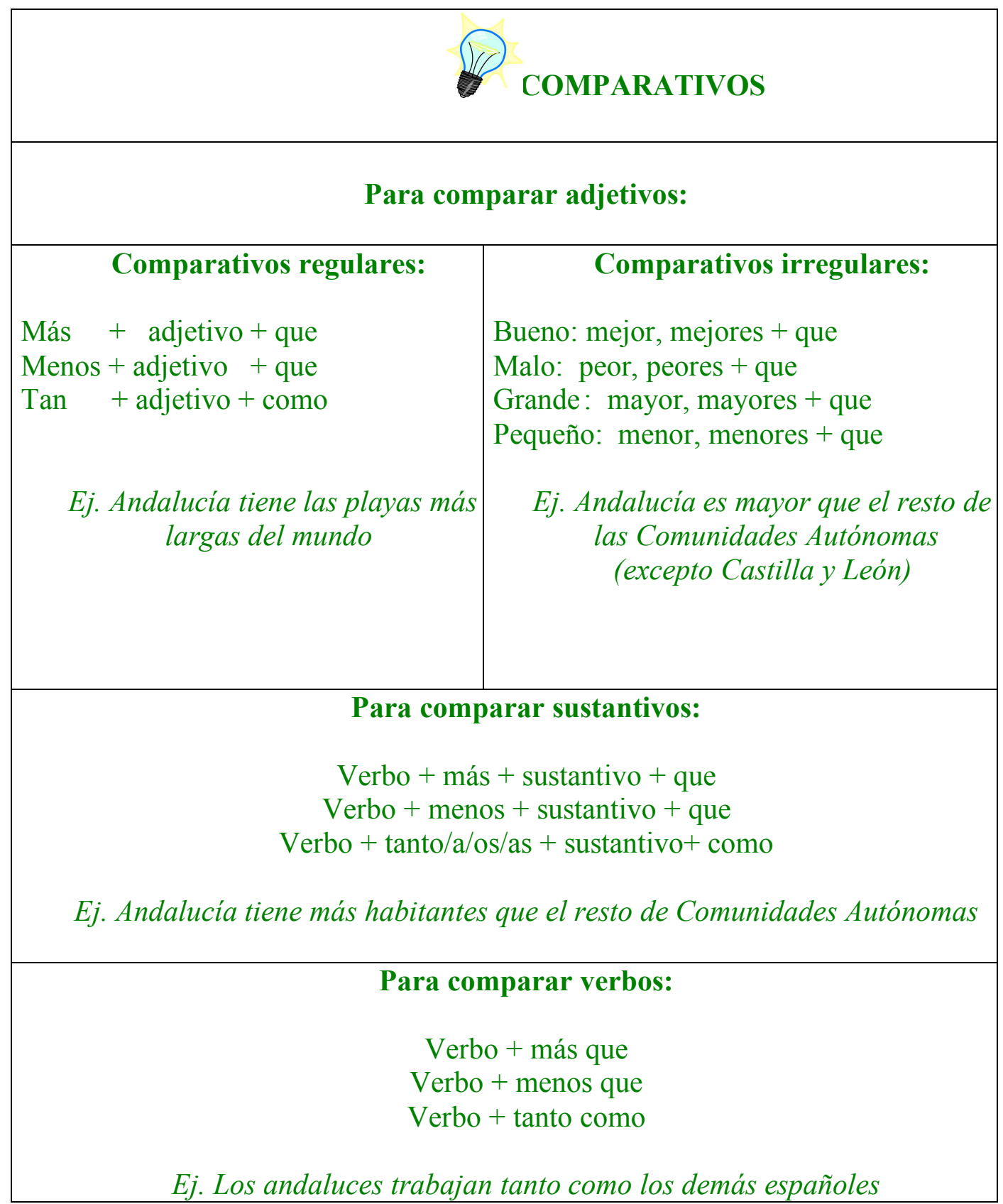


2. Observa la evolución de la publicidad en Andalucía. En grupo vamos a debatir sobre las distintas campañas publicitarias. Utiliza las frases comparativas

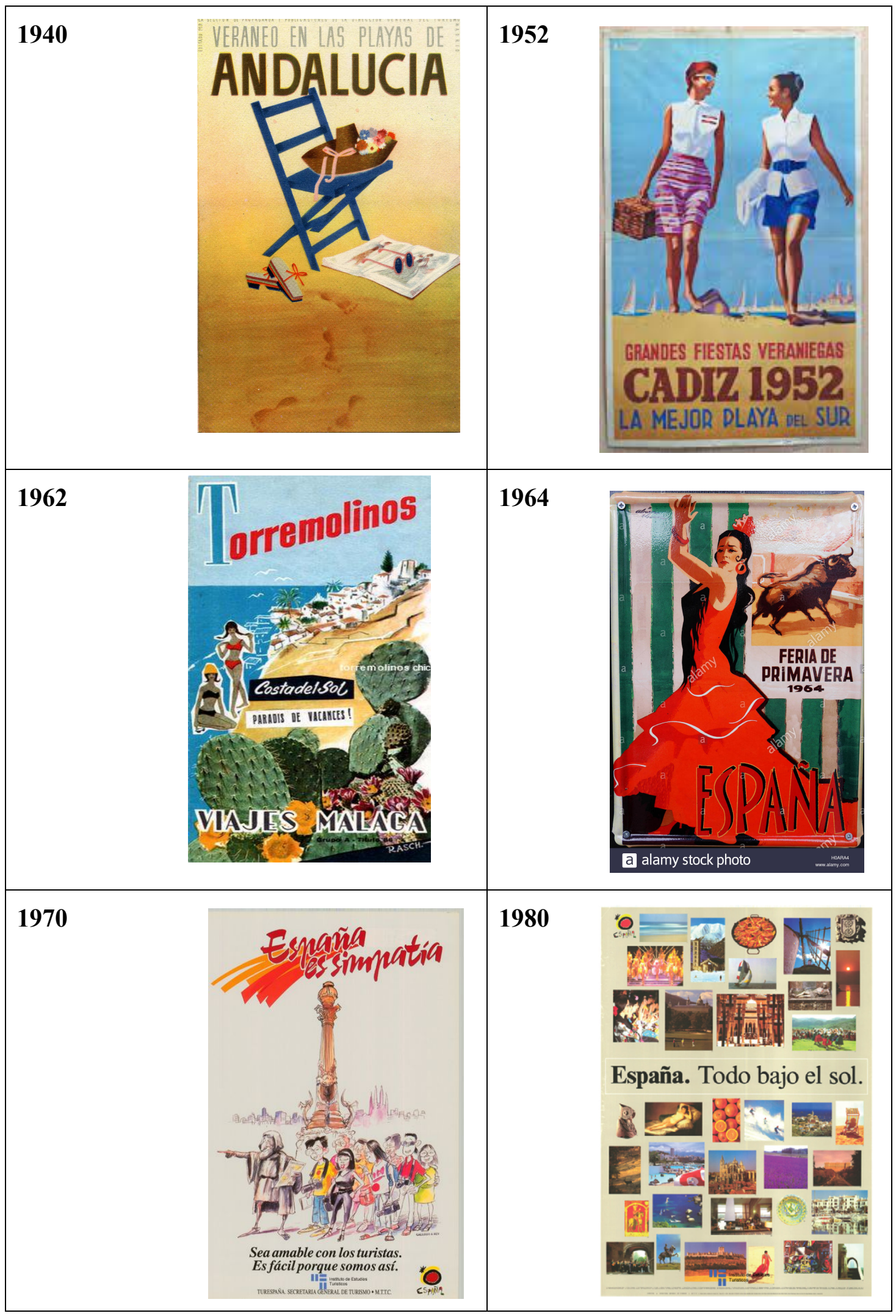




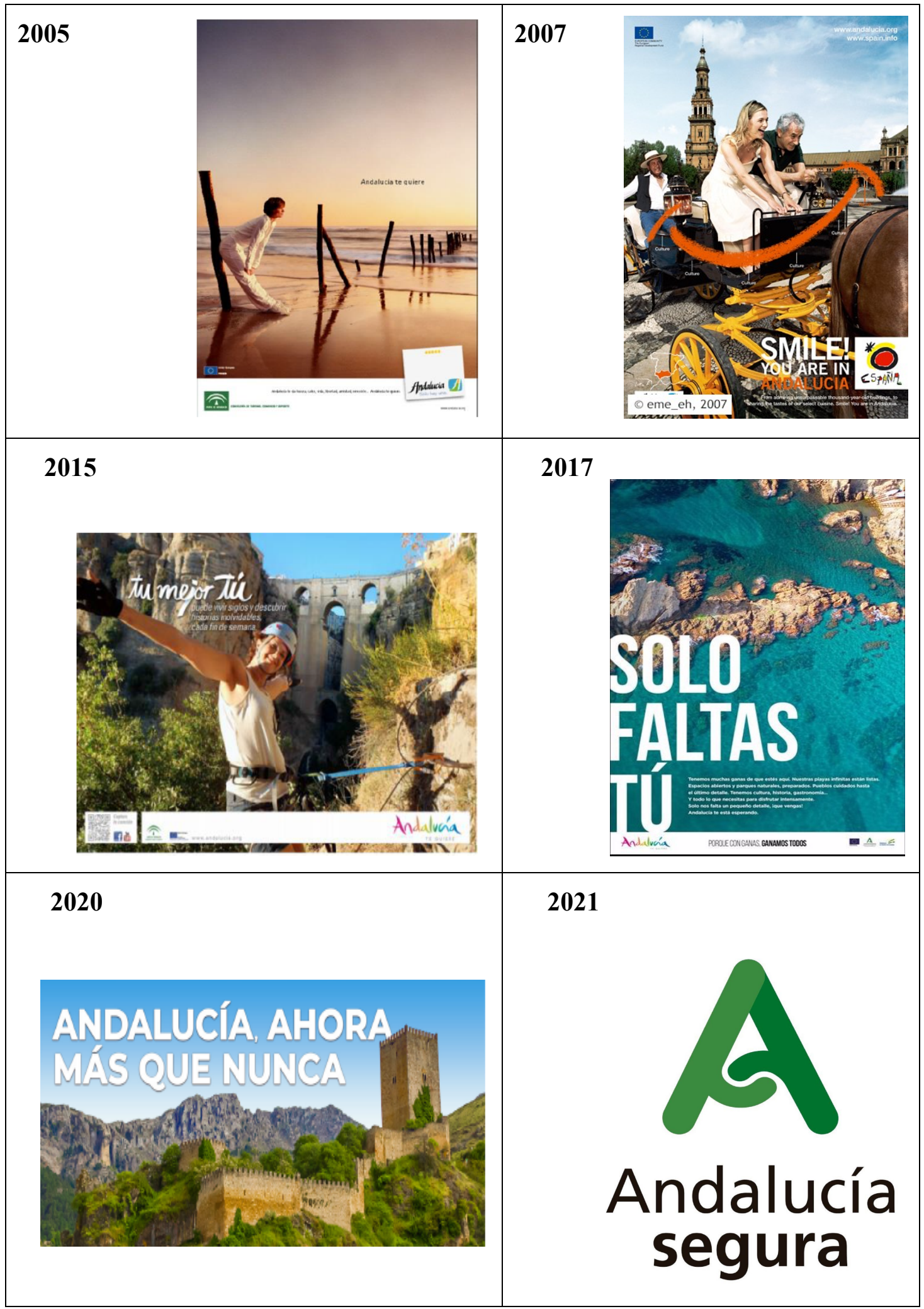

